\section{POR UMA POLÍTICA DE RECURSOS HUMANOS}

Virgilio Nelson da Silva Carvalho*

RESUMO: Análise da importância e necessidade de técnicas formais para treinamento e desenvolvimento de Recursos Humanos para a Hotelaria. Sugere uma maior consciemização sobre a mão-de-obra qualificada, a fim de melhorar a qualidade dos serviços na área de Hotelaria e Alimentação.

UNITERMOS: Hotelaria: recursos humanos: mão-de-obra qualificdda. Recursos humanos: hotelaria: restaurantes: treinamento; desenvolvimento; política.

ABSTRACT: Analysis of the importance and necessity of fornal techniques for the training and development Hotels Human Resources. It suggests a decper awareness about qualificd labor, in order to improve quality of the senices for the sector of hotels and restaurants.

KEY-WORDS: Hotel business: human resources; qualificd labor: Human resources: hotel industry; restaurants; training; cn iroment; politics.

\section{TREINAMENTO/DESENVOLVIMENTO PARA HOTÉIS E RESTAURANTES}

No desenvolvimento inicial da indústria de hotéis e restaurantes havia pouca necessidade de técnicas formais para treinamento de empregados. A antiga taverna era, normalmente, operada pelo proprietário com o auxílio da família e, ocasionalmente, com alguns empregados ou aprendizes. Ele aprendia a operação) do negócio com o pai ou durante um longo período de aprendizagem informal. Sua esposa cozinhava e as crianças (às vezes aprendizes ou empregados) eram instruídas por esta ou pelo próprio hospedeiro na manutenção da casa, preparo da alimentação e serviço.

(*) Diretor da Escola de Hotelaria João Dória Júnior. do Sindicato de Hotéis. Restaurantes. Bares e Similares (SHRBS) de São Paulo. Diretor de Desenvolvimento no Brasil da Meliá Hoteles.

End. para corresp.: Rua Jorge Americano. 380 - apto 54 - 05083 - São Paulo - SP Brasil.
O fim do século XIX foi testemunha de inúmeras modificações. A introdução de novos equipamentos e máquinas, bem como) o novo interesse pelos aspectos científicos da nutrição e higiene trouxeram a necessidade de treinamento formal. Na época, grandes empresas com dezenas e até mesmo centenas de empregados viram o aparecimento de novos problemas, entre os quais o treinamento para o trabalho. O antigo serviço das tavernas transformou-se em grandes operações de hotéis e restaurantes.

O problema de treinamento não se apresentou em toda a sua extensão até aparecerem as restrições à imigração da Europa na década de 1970. Europeus treinados nesse ramo desde a infância ansiavam por vir à América e atuar como empregados de cozinha e camareiras. Muitos "artesãos", em Portugal, chefes de cozinha e diaristas qualificados, procuravam trabalho nessa área na América.

As leis de imigração, contudo, praticamente cortaram essa fonte de suprimento de empregados e deixaram aos administradores de hotéis e restaurantes a alternativa de treinarem seus novos funcionários.

O efeito mais profundo dessas restrições à imigração não se fez sentir de imediato. Durante as décadas de 1970/80, forçados pela depressão, trabalhadores inteligentes e qualificados, saindo de outros ramos, foram obrigados a procurar emprego em restaurantes e hotéis. No entanto, o problema de treinamento tornou-se crítico. Com a retomada do crescimento da economia, não verificada no ramo de hotéis e restaurantes, esse setor deparou-se com a necessidade de expansão e a simultânea evasão do pessoal experiente, que se dirigia para outras atividades que pagavam altos salários com menos horas trabalhadas e com folgas regulares. A necessidade de empregados era premente. Praticamente qualquer um era contratado, mesmo sem a menor qualificação. Não é preciso dizer que a ineficiência era grande. Alguns dos maiores hotéis viram-se obrigados a empregar um número três vêzes maior de funcionários para executar o mesmo trablalho. A indústria de hotéis e restaurantes, conseqüentemente, conscientizou-se da necessidade de treinamento e desenvolvimento de Recursos Humanos.

Logicamente, essa não era uma situação no Brasil e especificamente em curso no ramo hoteleiro dos Estados Unidos. O governo federal reservou US\$ 100 milhões para aumentar e apressar o treinamento em toda a atividade industrial. Estabeleceu-se um serviço de treinamento dentro da indústria para iniciar e administrar um amplo programa de treinamento profissional. A repercussão foi notável. A partir das experiências desse programa, desenvolveram-se as técnicas de treinamento. 
Na década de 1960, principalmente, as grandes companhias como a Marriot ARA, Intercontinental Hotéis Corporation e as centenas de operações de serviços de alimentação no setor público empregaram especialistas em treinamento e, em alguns casos, estabeleceram departamentos de treinamento. Algumas associações estatais de restaurantes organizaram treinamento para garçonete e para higiene de alimentos. Grande parte do esforço das grandes companhias concentrou-se no esforço administrativo, preparando pessoal para cargos de gerência e supervisão. No Reino Unido, estabeleceram-se Comissões de Treinamento Industrial financiadas por meio da tributação imposta aos hotéis e serviços de alimentação. Os estabelecimentos que não se aproveitaram desse treinamento limitaram-se a subsidiar o treinamento para os concorrentes.

Nos Estados Unidos, grande parte dos esforços do Governo Federal voltou-se para o subsídio de treinamento de pessoas necessitadas por meio de contratos com hotéis e restaurantes. De fato, o governo federal estimulou o emprego de pessoal não qualificado, cobriu as suas despesas de subsistência durante o treinamento e, ao mesmo tempo, remunerou as empresas pelos esforços de treinamento.

Embora o ramo de hotéis e restaurantes dos Estados Unidos nunca o tenha considerado importante, o treinamento por aprendizado desapareceu quase que totalmente, à medida que escolas como o Instituto de Culinária da América e as escolas públicas tomaram a sua função de treinamento para qualificações.

Este artigo focaliza a importância e necessidade do treinamento e desenvolvimento de Recursos Humanos para a área de Hotelaria e Alimentação no Brasil, e as ações da EMBRATUR e do Sindicato de Hotéis, Restaurante, Bares e Similares de São Paulo.

\section{IMPORTÂNCIA DO TREINAMENTO PARA HOTÉIS} E RESTAURANTES

A grande maioria dos funcionários de hotéis, restaurantes e similares trata direta ou indiretamente com o público. Um defeito em uma peça de máquina ou um trabalho mal feito em um reparo não é tão notado como um fio de cabelo na sopa do cliente, ou um lençol sujo na cama do hóspede. O ramo da hotelaria/restaurante depende de um relacionamento direto com os clientes. $\mathrm{O}$ erro ou a ineficiência de um empregado pode fazer com que se perca o cliente para sempre.

Garçonetes, recepcionistas e telefonistas tratam diretamente com o público. O seu trabalho está sob a vigilância permanente dos hóspedes. Não está apenas sob a supervisão direta de um chefe, mas de todo o público. É extremamente necessário que eles saibam o que, c como fazer. Um hotel não pode se permitir contratar um recepcionista ou uma camareira que não tenham sido treinados. Um clube não pode se permitir cont

Característıcas de grande parte dos empregados dos hotéis e restaurantes, especialmente nos últimos anos, são as tendências de flutuar de um emprego para outro, de ter uma escolaridade relativamente baixa e de ser um tanto instáveis no aspecto emocional. Istoo não acontece com os empregados de muitos estabelecimentos bem organirados, onde prevalecem uma seleção e uma administração cuidadosa. Mas, geralmente, entre os empregados de hotéis e restaurantes verifica-se uma alta rotatividade causada, em parte, por essas características. Isso acontece principalmente nos cargos não qualificados, como operador de máquina de lavar pratos, lavador de panelas, auxiliar de cozinha e cozinheiro. Os cargos de garçon e auxiliar de garçon têm alta rotatividade. Nas centenas de hotéis de temporada existentes no País, é pequena a expectativa de continuidade da demanda o ano todo. Esses fatos significam que há grande necessidade de treinamento para se obter o nível desejado de desempenho dos Recursos Humanos.

Muitos dos empregados de hotéis e restaurantes não têm qualquer motivação para o trabalho a não ser a necessidade de dinheiro. Cerca de metade dos 400.000 empregados de hotéis são mulheres. Quase metade dos 1.800 .000 de empregados em restaurantes são mulheres. Muitas encaram seus empregos meramente como ocupações temporárias até o casamento ou algo melhor. Cerca de $25 \%$ dos empregados em restaurantes sāu dưlulescentes. Apenas uma pequena porcentagem pretende fazer carreira em hotéis ou restaurantes. ${ }^{2}$

Há necessidade de uma instrução detalhada. Um sanitarista do Estado de São Paulo narra um incidente que ilustra essa necessidade.

O gerente de um restaurante bem oryanizado cstara mostrando o noro e custoso equipamento para lavagem de pratos a um inspetor e ao secretário municipal de hi giene. O equipamento brilha' a de limpo: a temperatura da água para enuaguar estava entre os 17 e $18^{\circ} \mathrm{C}$ e a demonstração foi um sucesso - exceto por um pequeno detalhe: o operador da máquina, pego num momento de "rush", estav'a empilhando as xicaras de 3 em 3 na prateleira da máquina. $O$ jato de cima atingia apcnas a parte externa da terceira xícara: o interior da segunda e terceira nän era luvado. O pre dor resolvia o pequeno problema limpando o ucicar do fince das vicaras con dor resolvia o pequeno problema limpando o açícar do fundo das xicaras com uma
toalha.

Outro incidente semelhante serve para mostra que não se deve presumir o conhecimento até mesmo de elementos básicos do trabalho por parte do empregado: 
Um restaurante mais qualificado, com equipamento totalmente noro, foi inspecio. nado por um sanitarista do governo. Apesar dos dois aquecedores que elevavam a temperatura da água para $19^{\circ} \mathrm{C}$ no tanque, a temperatura da água na máquina de lavar pratos era de $153^{\circ} \mathrm{C}, 17^{\circ} \mathrm{C}$ mais baixa do que a temperatura aprovada de $170^{\circ} \mathrm{C}$ a $180^{\circ} \mathrm{C}$. A operaçào d̀ $153^{\circ} \mathrm{C}$ durou vários meses, com aparente satistą̧ào dos gerentes $e$ dos administradores. Parece que ninguém havia notado o mostrador de cemperatura, mesmo havendo uma flecha vermelha indicando a marca de $170^{\circ} \mathrm{C}$. A razão para esta queda de temperatura era uma extenção de 250 pés de entcana. mento sem isolantes térmicos entre a máquina de lavar pratos e o tanque de agua quente, portanto impedindo que o processo de aquecimento fosse eficaz na lavagem dos pratos.

O empregado médio de hotel ou restaurante semi-qualificado nāo se mostra satisfeito com qualquer tipo de treinamento em sala de aula. O empregado comum só está interessado no treinamento dotado de um objetivo real imediato. A teoria e a abstraçāo têm espaço limitado no treinamento de empregados. É quase impossível criar o interesse sem um objetivo imediato. $\mathrm{O}$ empregado deve ser lembrado constantemente de que o treinamento resolverá seus problemas sociais e econômicos, aumentará sua segurança e o valorizará como indivíduo. A maior parte do treinamento útil para hotéis e restaurantes envolve o ensino de novas habilidades a serem aplicadas imediatamente. Para os supervisores, essas habilidades podem incluir: como dar ordens, como repreender, como colocar uma idéia nova. Para os empregados, a habilidade pode ser: cortar bifes, arrumar camas, operar PBX ou preparar "Crepe Suzette".

\section{MUITOS CARGOS EM HOTÉIS E RESTAURANTES REQUEREM TREINAMENTO NO TRABALHO}

Um estudo do Departamento do Trabalho mostrou que quase todas as mulheres que trabalham em hotéis, principalmente camareiras, ascensoristas e recepcionistas e, até mesmo, algumas funcionárias administrativas estāo acima dos 35 anos. Quase metade está acima dos 45. Os homens também sāo de uma faixa etária mais velha.

Nos hotéis, principalmente entre mensageiros e recepcionistas, uma porcentagem considerável dos empregados já passou de 25 anos. Os funcionários que começam no emprego com idade superior têm, normalmente, menos motivação do que aqueles que escolheram o trabalho quando jovens. Assim, torna-se necessário propiciar um treinamento melhor para o grupo mais velho.

De acordo com o falecido consultor de hotéis Fred Ecker, $62 \%$ do total da folha de pagamento de um hotel encontra-se em mão-de-obra nāo qualificada e semi-qualificada, que precisa ser treinada no hotel e instruída no serviço. Dessa porcentagem, dois terços abrangem traba- lhadores nāo qualificados: camareira, garçons, auxiliares de garçon, vadores de pratos, zeladores, carregadores, faxineiros, jardineiros, bombeiros. O outro terço engloba os funcionários da recepção, caixas, ascensoristas, telefonistas, mensageiros, encarregados de bar, alimentos e armazéns, vigias, chefes júnior de departamento de supervisāo.

$\mathrm{Na}$ verdade a responsabilidade final deve ser de um supervisor e nāo de um "treinador" profissional que vai de um lugar ao outro, ou alguém do departamento pessoal. É o supervisor que recompensa ou pune o empregado, quem se beneficia ou se prejudica com o treinamento ou com a falta dele. Desde que a maioria dos empregados dos hotéis e restaurantes sāo de natureza semi-qualificada, eles podem e devem receber treinamento no próprio ambiente de trabalho. $\mathrm{O}$ treinamento administrativo e para os chefes de cozinha é algo diferente, e que requer vários meses mesmo quando apresentado de maneira sistemática. gados:

A seguir, algumas vantagens advindas do treinamento dos empre-

a) Aumento da Velocidade de Aprendizagem

O aprendiz nāo precisa procurar pelo método de tentativa e erro acidental. Com a instrução, sua velocidade é aumentada e seu nível de desempenho de eficiência é alcançado mais cedo.

Por meio de um programa eficaz de treinamento, o empregado se adapta mais depressa ao trabalho. Suas tensões emocionais são reduzidas com a ajuda que se lhe oferece para evitar erros.

O interesse apresentado pelo instrutor age como um estímulo para o aprendizado. $\mathrm{O}$ aprendiz chega mais depressa a um estágio de produção plena.

b) Aumento de Qualidade de Desempenho

Aprendendo a maneira correta de executar o trabalho, o aprendiz evita incorrer nas maneiras incorretas. Ensinar implica em compartilhar os melhores métodos descobertos através da experiência de uma série de pessoas. Apenas os melhores métodos são ensinados.

c) Menos Quebra e Estrago de Material

A maioria dos trabalhos envolve quebra e estrago de material, seja o trabalho de uma empregada, de um lavador de pratos ou do peixeiro. Um trabalhador inexperiente e nāo treinado pode custar muito dinheiro à operação. Um estudo das indústrias do Estado de Nova York mostrou que o treinamento reduzia o estrago a $73 \%$. O treinamento pode ser um seguro contra quebra e estrago. Uma administração precavida adota o valor de um seguro. ${ }^{3}$ 
4 PRODUZIR A TODO CUSTO RESISTINIDO A QUALQUER PREÇO - Recursos humanos: um grande custo ou um pequeno investimento?

No Brasil, muito tem sido feito c usado em funçāo de seu potencial, que nem sempre corresponde a um potencial real mas a uma fantasia empresarial de poucos, com pouca experiência, que se aventuram numa nova área, setor ou segmento econômico, sempre incentivados ou subsidiados por açōes do governo (vide exemplos nas árcas da atuaçāo da SUDENE, SUDAN etc.)

O gargalo atual da produçāo, crescimento e desenvolvimento de todas as atividades direta ou indiretamente ligadas ao Turismo, está na questāo de Recursos Humanos, quer em sua quantidade ou qualidade. A decantada-encantada principal atraçāo turística do Brasil, a hospitalidade, está em falta no mercado, ocasionando perdas irreparáveis para o "trade" turístico nacional. Isto porque durante os últimos anos viveu-se num regime de desemprego, com índices de ate $10 \%$ ao ano. Nesta situação, a hotelaria passa a trabalhar com os excedentes do mercado, pois com seus baixos salários e poucas exigências de especializaçāo, recolhe a sobra do mesmo. Constituiu-se, juntamente com a Construçāo Civil, num mercado paralelo marginal, que absorve a todos, elevando, assim, o "turn over" da atividade a índices por volta de $8 \%$ ao mês, com uma permanência média de 11 meses para $70 \%$ do quadro de funcionários de um Hotel. Portanto, de um ano para outro, um hotel troca $70 \%$ de seu quadro de pessoal. Com isso, quem consegue manter padrões de serviço e controlar a qualidade? "Haja escolas, centros, cursos, seminários e pessoas para atender tamanho devorador de profissionais!"

Os profissionais mais especializados, por sua vez, continuam de hotel em hotel, procurando melhores condiçōes de trabalho, salários, benefícios e qualidade de vida.

Esse quadro representa um passado tāo próximo que se confunde com o presente, mixando-se no futuro, pois o desenvolvimento turístico do País como um todo, e hoteleiro em especial, está relacionado ao fator Recursos Humanos, em termos de quantidade, qualidade e especializaçāo, dado que cada vez mais deverá influir na rentabilidade c no resultado líquido dos seus empreendimentos.

Com a vinda, em "franchises" ou "managments", de algumas companhias internacionais e mesmo nacionais, vem-se desenvolvendo as mais avançadas tecnologias no setor, criando o desenvolviment() de móveis, equipamentos, utensílios e demais sistemas afins.
Infelizmente na área de Recursos Humanos pouco ou nada se conseguiu evoluir, pois as empresas internacionais tendem a recrutar no exterior seus técnicos de operaçāo, "controllers", homens de marketing etc. No Brasil, a transferência de tecnologia ocorreu sem o acompanhamento do recurso humano habilitado, seja recrutado no exterior, seja formado e treinado no País.

A verdade é que já nāo se vive mais a época da força de trabalho abundante e qualificada. Agora faltam recursos humanos, uma vez que a atividade turística e hoteleira nāo valorizou os que para ela trabalhavam e se esforçaram para o seu sucesso. Há a necessidade de profissionais e nāo mais de māo-de-obra sem qualificaçāo; precisam-se empregados que possam ser profissionais e que muitas vezes foram para a indústria, o comércio etc. Para recuperá-los tem-se que fazer muito e, fundamentalmente, reavaliar, consciente e empresarialmente, com visăo de futuro, as novas políticas de recursos humanos.

Enumeram-se abaixo, alguns itens sobre os quais devem-se, individualmente e em grupo, fazer uma reflexāo profunda.

a) Recrutamento. Seleçâo. Contrataçāo (Fim de Pirataria).

b) Ambientação (o que espera-se da Empresa. O que se pode dar).

c) Treinamento nos Padrōes de Serviço da Empresa.

d) Desenvolvimento Profissional (adestrar ou desenvolver?).

e) Avaliação de Desempenho (Orientaçōes aos 30, 60, 90 e 180 dias).

f) Benefícios.

g) Plano de Cargos e Salários/Carreiras.

h) Desenvolvimento de Chefias.

i) Perfis de Funçāo.

j) Pesquisa Salarial (Fim de "tourn over"). ${ }^{4}$

\section{DE VOLTA O FANTASMA DAS DEMISSÕES E}

\section{A FALTA DE PROFISSIONALISMO NO MERCADO}

Considerando o momento econômico, as indefiniçōes políticas e, por conseguinte, as açōes empresariais, todos os brasileiros sofrem com a crise. Investimentos suspensos, negócios em compasso de espera levam os dirigentes a exercitar e a preparar planos emergenciais para proteger suas empresas, incluindo normalmente a revisāo do quadro e custos de sua māo-de-obra.

Sensível à diminuiçāo da ocupaçāo hoteleira, o quadro de pessoal é atingido diretamente, ocasionando o "tourn over", tāo prejudicial à atividade emergente que é o turismo, prejudicando o seu padrāo de serviços e controle de qualidade. Normalmente os gerentes da área 
não conduzem a contento o processo de demissão. Se dispensar é preciso, precisa-se enfrentar com naturalidade, administrando-a de maneira objetiva e humana, diminuindo ao máximo a crise das pessoas e da organização.

A demissão de Recursos Humanos à nível operacional, técnico ou gerencial nessa área apresenta diferentes causas e efeitos:

a) para a empresa: é só selecionar o cargo, a função e por fim o nome do funcionário, comunicar-lhe a decisão, explicar os motivos e conviver com o mal estar do grupo, que permanece até a recomposição do grupo novamente, com custos muitas vezes imensuráveis;

b) para os gerentes: é um processo difícil, pois perde um profissional e uma vaga, além do sentimento social para com o demitido; o fato é angustiante para ambos;

c) para o profissional: sempre como surpresa, atordoado ele perde até o sentido da dedicação feita durante certo tempo para aquela empresa; sente-se incompetente, sem perspectivas futuras.

Nesses casos normalmente surgem os de pouca e muita dedicação à empresa que levam a um desgaste maior na relação capital x trabalho. A dispensa de um profissional não é um fato estanque ou isolado, atinge todo o grupo de empregados e membros da família.

Para a empresa, a dispensa precipitada pode colocar a mesma mal posicionada no mercado, criando uma imagem negativa junto aos futuros profissionais, aos consumidores e à concorrência. Com um funcionário normalmente saem gastos desnecessários de R.H., além do "know how" armazenado durante todo o tempo em que esteve na empresa. Quando isto acontece com uma determinada empresa, normalmente acontece com todas as outras, estagnando e, em seguida, retraindo o mercado. Uma solução a ser pensada será a transferência de funcionários para outras atividades na mesma empresa, visando melhores oportunidades.

Em síntese, quando dispensar é preciso, deve-se estabelecer uma política de demissōes atentando para:

a) esgotar todas as possibilidades antes de demitir;

b) custos de demissão e novas admissōes futuras;

c) "know how" perdido;

d) imagem da empresa junto a clientes, Recursos Humanos, opinião pública;

e) responsabilidade do chefe imediato na admissão e demissão;

f) revisão do processo de seleção, treinamento e acompanhamento dos funcionários na empresa

g) outros.
Quando a demissão é necessária deve-se estabelecer critérios baseados em:

a) identificar pessoas para novas funçōes;

b) identificar pessoas com menores encargos pessoais;

c) identificar pessoas com melhor possibilidade de re-colocação.

Quando o conceito da força capital colabora com a força trabalho neste período crítico, normalmente as causas negativas das demissōes são abrandadas, devendo-se avaliar, com critérios e cuidados, antes de cada demissão.

\section{BIBLIOGRAFIA}

1. CENTRO DE FORMAÇÃO TURÍSTICA E HOTELEIRA. Padröes teóricos das exigências psicológicas para cargos em hotelaria e aurismo. Lisboa. C.F.T.H., 1982. 2. Ministério do Trabalho. Levantamento da mäo-de-obra. Brasilia, MT, 198.5.

3. SENAC. Demanda de mäo-de-obra e necessidades de treinamento para hotćis c restaurantes. São Paulo. SENAC - Depto Regional. 1972

4. SERSON, José. Curso Básico de adininistraçào do pessoal. São Paulo. LTR. 1986. 